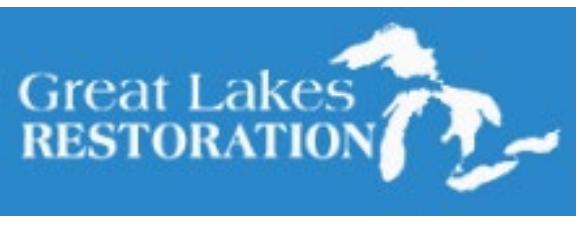

\title{
Evaluating Soil Phosphorus Storage Capacity in Constructed Wetlands: Sampling and Analysis Protocol for Site Selection
}

\author{
by Christine M. VanZomeren and Jacob F. Berkowitz
}

PURPOSE: Soil characteristics determine the capacity of wetlands to sequester phosphorus (P). ${ }^{1}$ However, researchers have not yet developed a standard protocol for conducting soil sampling to document the soil phosphorus storage capacity (SPSC) for constructed wetland site selection. In response, the following technical note provides step-by-step instructions for selecting soil sample locations, describing site conditions, conducting soil sampling, and preparing samples for laboratory analysis. This note also includes calculations and interpretation of SPSC.

BACKGROUND: The Great Lakes Restoration Initiative (GLRI) identified reduction of P loading in Great Lakes watersheds as a priority item to address degraded water quality at regional scales (Great Lakes Water Quality Agreement 2012; Great Lakes Restoration 2014). Recent interest focused on the use of constructed wetlands (that is, P-optimal wetlands) to capture excess nutrients from agricultural runoff and other sources (Merriman 2015). In response, efforts are underway to identify locations to construct, expand, or improve wetland $\mathrm{P}$ retention within target watersheds (Berkowitz et al. 2019). However, wetland soils have a limited capacity to retain $\mathrm{P}$, and soil chemistry must be considered throughout the planning, implementation, and operational phases of project development (Currie, VanZomeren, and Berkowitz 2017; VanZomeren et al. 2019). The incorporation of soil data (that is, SPSC) into project design and management supports implementation of the P-optimal wetland approach, a regional initiative to utilize wetlands as a part of a larger nutrient reduction strategy. A soil sampling protocol instructing user groups to properly conduct soil sampling will assist with the development and implementation of P-optimal wetlands. This technical note also discusses interpretation of soil data to inform resource managers about soil $\mathrm{P}$ conditions at potential wetland construction locations. In some cases, in situ soils may not have the capacity to retain additional $\mathrm{P}$, or may be a potential $\mathrm{P}$ source, and require management strategies to address soil $\mathrm{P}$ saturation.

SPSC SAMPLING PROTOCOL: The soil sampling protocol outlined below supports site selection and evaluation of P-optimal constructed wetlands through the assessment of SPSC. The protocol will ensure consistent soil sampling, analysis, and interpretation of data across user groups, promoting the use of science-based decision making at regional scales. The protocol

1. For a full list of the spelled-out forms of the chemical elements used in this document, please refer to $U S$ Government Publishing Office Style Manual, 31st ed. (Washington, DC: US Government Publishing Office, 2016), 265, https://www.govinfo.gov/content/pkg/GPO-STYLEMANUAL-2016/pdf/GPO-STYLEMANUAL-2016.pdf. 
includes details on collecting and recording relevant information on site characteristics and proper soil sampling. The protocol also includes necessary field tools and additional information for soil sampling.

SITE CHARACTERIZATION AND SAMPLE LOCATION SELECTION: Site characterization includes pertinent information related to soil sample site locations, soils information, and other observations (for example, vegetation, management practices, or disturbances) necessary to interpret soil data and inform resource managers. Researchers and resource managers can record site characteristics using the US Army Corps of Engineers (USACE) wetland delineation forms available at https://www.lre.usace.army.mil/Missions/Regulatory-Program-and-Permits /Automated-Wetland-Determination-Data-Form. We include a sample completed version of the soil data portion of the form below (figure 1).

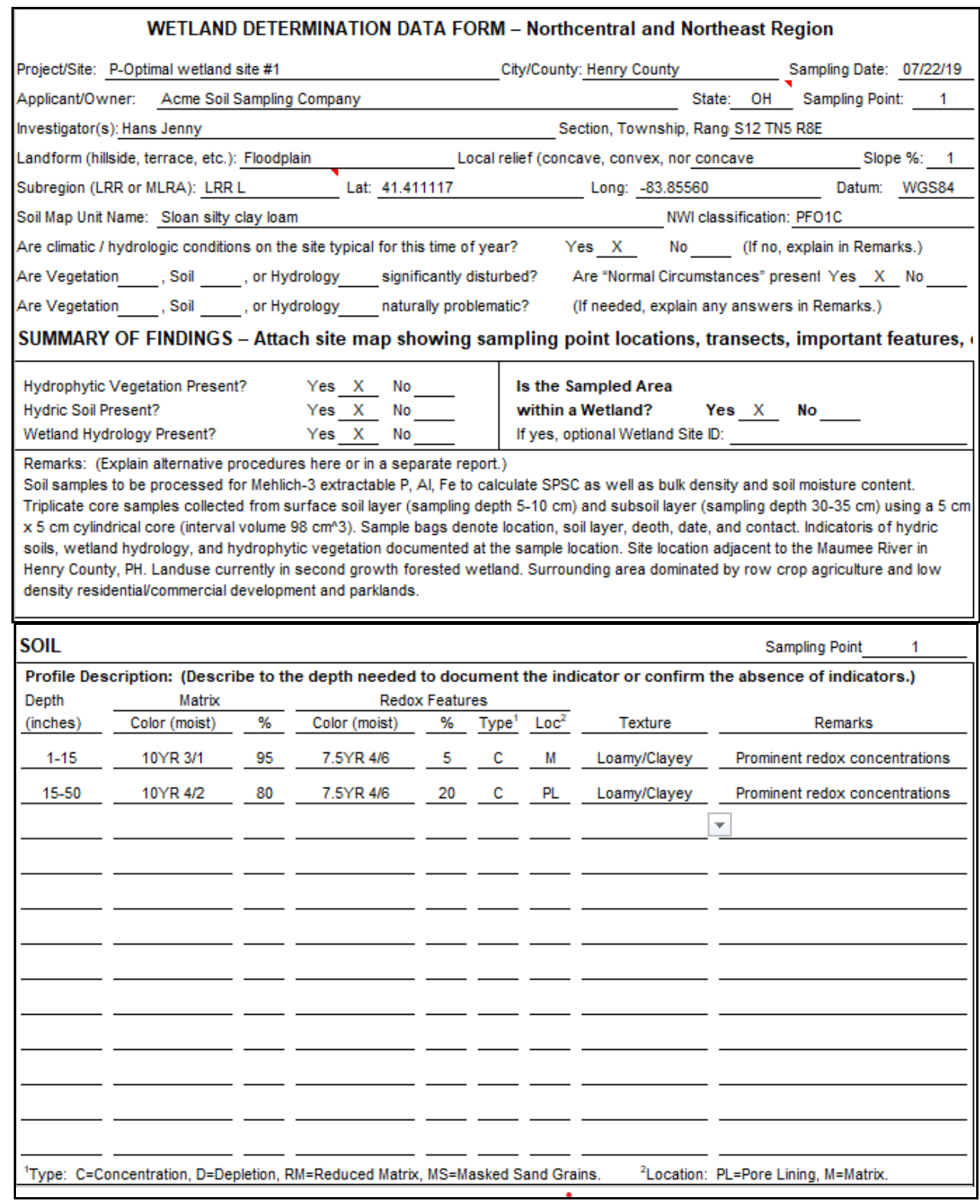

Figure 1. Example of a completed site description and soil data form. 


\section{Protocol for site characterization.}

1. Record the date, site name, above- or belowground water level, dominant vegetation community type, slope, wetland type (National Wetland Inventory classification, hydrogeomorphic classification, etc.), soil series (if known) and GPS coordinates with datum on the data form.

2. Select sample locations based on representative soil conditions. Soil sampling should reflect the general soil conditions observed within the area. Visually evaluate soils in several shallow soil pits $\left(\sim 50 \mathrm{~cm}^{2}\right.$ deep) within each site to determine the variability of soil materials across the site.

Establishing several screening transects can aid in determining the degree of soil heterogeneity, especially in large or heavily disturbed areas. After examining the screening pits, select one or more representative sample locations for soil collection.

3. At each representative sample location, complete the basic soil description form indicating the depth of the soil layers present, the matrix color of each soil layer using the Munsell book (X-Rite 2009), redoximorphic feature colors and abundances (if present), and the soil texture for each soil layer observed within the upper 30-50 cm of the soil surface (figure 1). Additional guidance for conducting basic soil descriptions is provided in US Army Corps of Engineers (2012) and Vasilas and Berkowitz (2015).

4. If the sample area is small ( $<4 \mathrm{ha}$ ) and homogenous in terms of topography, soils, management, vegetative community types, and, fill out only one data form. However, if the site is $>4$ ha or characteristics vary across the site, fill out multiple data forms representing each of the observed site conditions.

5. Add additional relevant information in the remarks section and as appendices to the data form. Supplemental information may include a map with sampling locations identified, photos depicting site conditions, and information related to past and present land management (that is, farming practices, soil compaction, and topographic relief).

SOIL SAMPLING MATERIALS: The materials and tools required for soil sampling and their purpose in the protocol are listed below in counterclockwise order (figure 2).

- $\quad$ soil sampling protocol (this document): guide for SPSC sampling

- sealable plastic sample storage bags: store soil sample

- labels: identify sample location, soil layer, sampling depth, and contact information

- Munsell color book: document soil matrix and redoximorphic feature color

- permanent markers, pencils, pens: complete data forms and labels

- cylindrical soil cores (for example, $5 \mathrm{~cm} \times 5 \mathrm{~cm}$ cores): collect soil samples - minimum three cores recommended

- $\quad$ soil knife: excavate soil cores and transfer soil samples to sample bags

2. For a full list of the spelled-out forms of the units of measure used in this document, please refer to $U S$ Government Publishing Office Style Manual, 31st ed. (Washington, DC: US Government Publishing Office, 2016), 248-52, https://www.govinfo.gov/content/pkg/GPO-STYLEMANUAL-2016/pdf/GPO-STYLEMANUAL2016.pdf. 
- small mallet or sledgehammer: facilitate inserting soil cores into dry/hard soil layers

- measuring tape: document soil layer and soil sampling depths

- sharpshooter shovel or drain spade: excavate soil pit prior to sample collection

- data forms (appendix): document site conditions related to SPSC

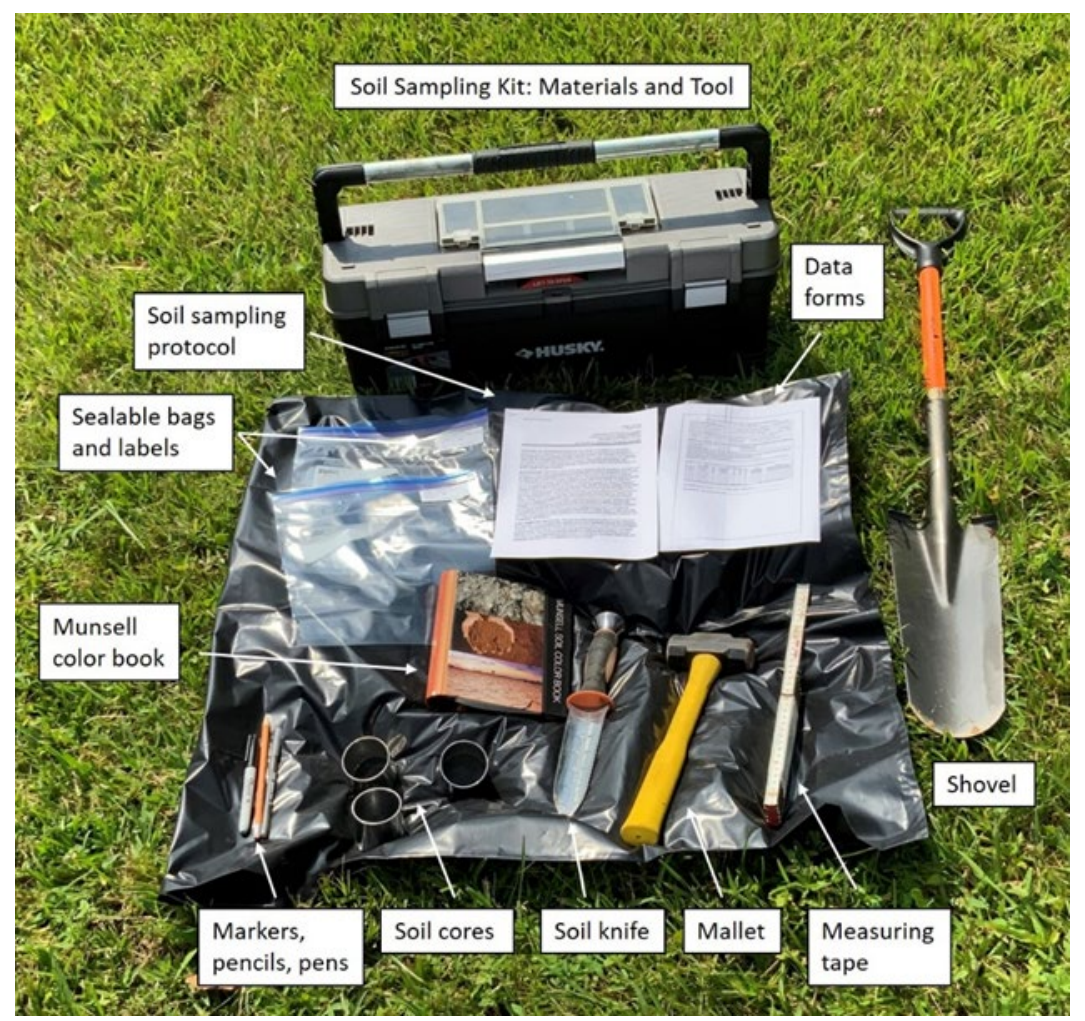

Figure 2. Example soil sampling kit, including necessary materials and tools.

SOIL SAMPLING APPROACH: Vertical stratification of soil P often occurs in soils used for current or historical agricultural production, with higher $\mathrm{P}$ concentrations in the near surface soil materials (often within the upper $2-5 \mathrm{~cm}$; Baker et al. 2017). To account for this tendency, collect soil samples to assess SPSC in both surface and subsurface mineral soil layers. In most cases, these layers represent the A and B- soil horizons. The A horizon (that is, topsoil) represents the major rooting zone in most soils and typically occupies the plowed zone in agricultural settings. The $\mathrm{B}$ horizon represents a zone of soil constituent accumulation and will often exhibit elevated concentrations of clay $\left(B_{t}\right)$, iron $\left(B_{s}\right)$, or organic matter $\left(B_{h}\right)$ translocated from the overlying soil layers. In some cases, soil collectors may encounter other soil horizons (that is, $\mathrm{O}$ or E horizons), and assistance from a soil scientist with local experience can help determine the most appropriate sampling approach on a site-specific basis. The protocol described herein uses cylindrical soil cores (for example, $5 \mathrm{~cm} \times 5 \mathrm{~cm}$, internal volume $=98$ $\mathrm{cm}^{3}$ ) driven into the soil using a small mallet or sledgehammer. Combine triplicate soil cores into a single soil sample bag and homogenize prior to analysis (figure 2). This approach accounts for the inherent variability in soil properties and the use of a known soil core volume allows for extrapolation of results to a field scale if oven dried soil moisture content and bulk density are 
also known. Other soil sampling devices, core sizes, and approaches exist and can be adapted to this protocol.

\section{Protocol for surface soil sampling.}

1. At each selected sample location, fill out the sample label information and place the label on the soil sample bag (figure 3 lower left).

2. Note that the same data form can apply to multiple soil sample locations if the soil descriptions, landscape position, and other factors remain consistent. If using multiple samples with that same form, note the corresponding sample numbers on the data form.

3. Remove aboveground vegetation from a small $1 \mathrm{~m}^{2}$ area (figure 3 upper left and right).

4. Excavate a soil pit 50-100 cm in depth. The soil pit should be large enough to (a) evaluate the near-surface soil layers present and (b) access surface and subsoil layers during sample collection.

5. Determine the appropriate soil sampling depth. Generally, we recommend collecting soil samples from the midpoint of the surface layer to avoid excessive plant roots and transitional features associated with surrounding soil layers. For example, if the A horizon is $15 \mathrm{~cm}$ thick, conduct soil sampling at a depth of 5-10 cm. Record the sample depth on the sample label (figure 3 middle).

6. Insert the soil core to the desired sample depth (for example, 5-10 cm), ensuring that the soil core is full (figure 3 upper right). Drive the soil core gently into the soil to avoid soil compaction to the extent possible. If the soil is moist and friable, cores may be inserted into the soil by hand. In most cases, a small mallet or sledgehammer will assist with sample collection.

7. Users may need to dig around the outside of the soil core with a shovel or soil knife to loosen the surrounding soil material. Make sure the soil does not fall out of the bottom of the core during removal or get compacted during sample collection. If the soil core is not full upon removal, or if compaction has occurred, remove the soil from the core and repeat the sampling process. Remove excess soil around the side or bottom of the core prior to placing the soil into the labeled sample bag. If the core is full, not compacted, and no excess soil protrudes from the end of the core, remove the soil sample from the core and place it into the labeled sample bag ensuring that all soil within the sample core is collected into the bag. The soil knife is often useful for transferring the soil from the core into the labeled sample bag, particularly if the soil contains clay. Ensure that no soil remains on the interior of the sampling core.

8. Repeat steps 6 and 7 at two additional locations within the $1 \mathrm{~m}^{2}$ sample area, placing the three surface-layer soil cores into the same plastic bag (figure 3 middle). 


\section{Select and area to collect}

three replicate soil cores
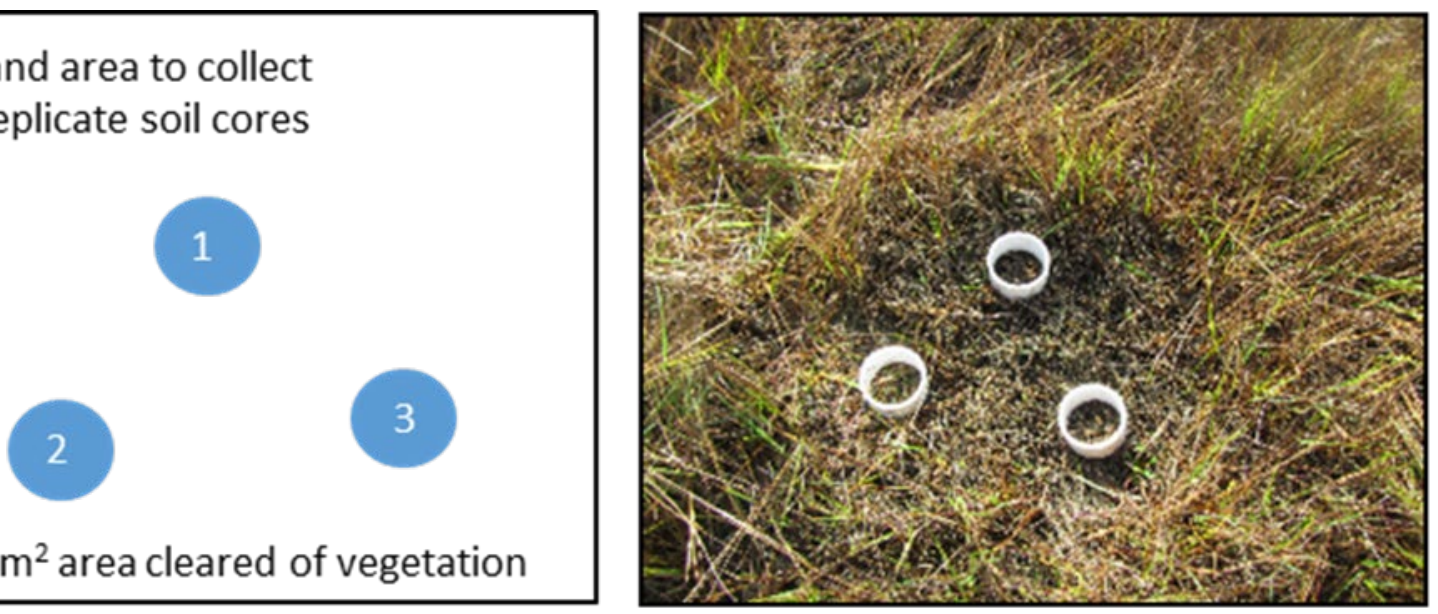

$929 \mathrm{~cm}^{2}$ area cleared of vegetation

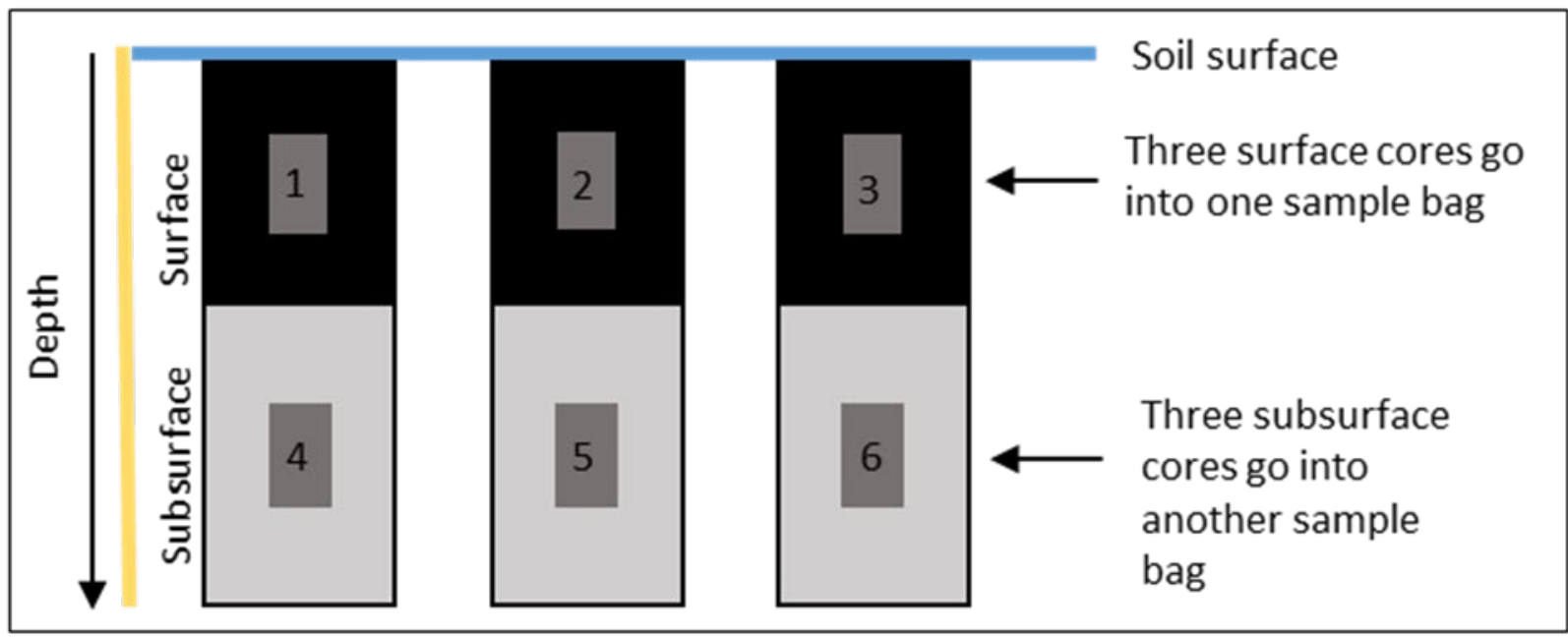

\begin{tabular}{|c|c|c|c|}
\hline \multicolumn{2}{|c|}{ Phosphorus Optimized Wetlands } & \multicolumn{2}{|c|}{ Phosphorus Optimized Wetlands } \\
\hline Site: & Sample: Surface & Site: & Sample: Subsurface \\
\hline Date: & Depth: & Date: & Depth: \\
\hline \multicolumn{2}{|c|}{ Data Form \#: 1} & \multicolumn{2}{|c|}{ Data Form \#: 1} \\
\hline \multicolumn{2}{|c|}{ Contact: } & \multicolumn{2}{|c|}{ Contact: } \\
\hline
\end{tabular}

Figure 3. Aboveground view of soil sampling locations (top left diagram and photo); side view indicating proper surface and subsoil cores collection (middle diagram); example labels for surface and subsoil soil sample bags (bottom diagram).

\section{Protocol for subsoil sampling.}

9. Fill out the sample label information and place the label on the soil sample bag.

10. Determine the desired soil sampling depth. Generally, we recommend collecting subsurface soil samples from the midpoint of the subsurface horizon to avoid transitional features associated with surrounding soil layers. For example, if the B horizon begins at $20 \mathrm{~cm}$ and extends to $35 \mathrm{~cm}$, 
conduct soil sampling at a depth of $25-30 \mathrm{~cm}$. If the lower extent of the subsoil horizon cannot be determined, collect the soil sample at a depth at least $5 \mathrm{~cm}$ below the transition zone with the soil layer above. Record the sample depth on the sample label.

11. Insert the soil core to the desired sample depth (for example, $25-30 \mathrm{~cm}$ ), ensuring that the soil core is full.

12. Use a shovel or soil knife to dig around the outside of the core, ensuring minimal compacting and soil loss.

13. Repeat steps 11 and 12 at two additional locations within the $1 \mathrm{~m}^{2}$ sample area, placing the three subsurface soil cores into the same plastic bag.

SOIL STORAGE, SHIPPING, AND ANALYSIS: Once sampling is complete, store soils at room temperature and away from light prior to transporting to the laboratory for analysis. Note that the determination of SPSC is not a common procedure conducted at commercial laboratories, university extension service centers, or most universities. However, the analytical methods used to determine each SPSC component are common, and researchers can easily calculate SPSC based on laboratory testing results.Consequently, researchers and resource managers must work with their selected laboratory to ensure (a) that soil handling and storage are conducted in accordance with requirements of that facility and (b) that the laboratory analysis results allow for SPSC calculation (see description below). Generally, soils are air dried by spreading soil onto a clean, dry surface (for example, clean paper) prior to shipping to the soiltesting laboratory. This decreases the sample weight and associated shipping costs. However, we recommend taking measurements of soil moisture content and bulk density (Reddy et al. 2013) for researchers who want to extrapolate SPSC results to a volumetric basis.

CALCULATIONS AND INTERPRETATION: The SPSC calculation is based on Mehlich-3 extraction data in $\mathrm{mg} \mathrm{L}^{-1}$ (Mehlich 1984) that estimates the remaining capacity for a soil to retain P. Calculate the SPSC using the following formulas (Nair et al. 2013), where the threshold P saturation ratio (PSR) of 0.10 is used in accordance with Nair et al. (2004), Dari et al. (2018), and VanZomeren et al. (2019)

$$
\operatorname{SPSC}\left(\mathrm{mg} \mathrm{P} \mathrm{kg}^{-1}\right)=(0.10-\text { Soil PSR }) \times\left(\text { Mehlich-3 }-\left[\left(\frac{\mathrm{Fe}}{56}+\frac{\mathrm{Al}}{27}\right) \times 31\right]\right)
$$

and where the soil PSR is calculated as the molar ratio of Mehlich-3 extractable P to Mehlich-3 extractable $\mathrm{Fe}$ and $\mathrm{Al}$

$$
\operatorname{PSR}=\frac{\left(\text { Mehlich-3 }-\frac{\mathrm{P}}{31}\right)}{\left[\left(\text { Mehlich-3 }-\frac{\mathrm{Fe}}{56}\right)+\left(\text { Mehlich }-3-\frac{\mathrm{Al}}{27}\right)\right]}
$$


In some cases, adjustment of the threshold PSR of 0.10 is needed based on differing soil types from those described in Nair et al. (2004) and Dari et al. (2018). The SPSC distinguishes soils that are a potential sink (green), source (red), or flow-through (yellow) system for P (figure 4). Where SPSC is positive, soils may retain P (sink). Where SPSC is negative, soils may leach P (source). Soils with an SPSC near zero are neither strong sources nor sinks for P and likely represent a flow through system for $\mathrm{P}$.

SUMMARY: Wetlands have the potential to improve water quality by retaining excess $\mathrm{P}$ through soil-water interactions. Efforts are underway in the Great Lakes region to identify locations to construct, expand, or improve wetland $\mathrm{P}$ retention within target watersheds. However, soil $\mathrm{P}$ concentrations can limit or exceed the capacity of a soil to retain additional $\mathrm{P}$. To construct and implement a successful P-optimal wetland, soil chemistry must be considered throughout the planning, implementation, and monitoring phases. This soil sampling protocol will aid consistent soil sampling, analysis, and interpretation of soil data through the use of the SPSC approach.

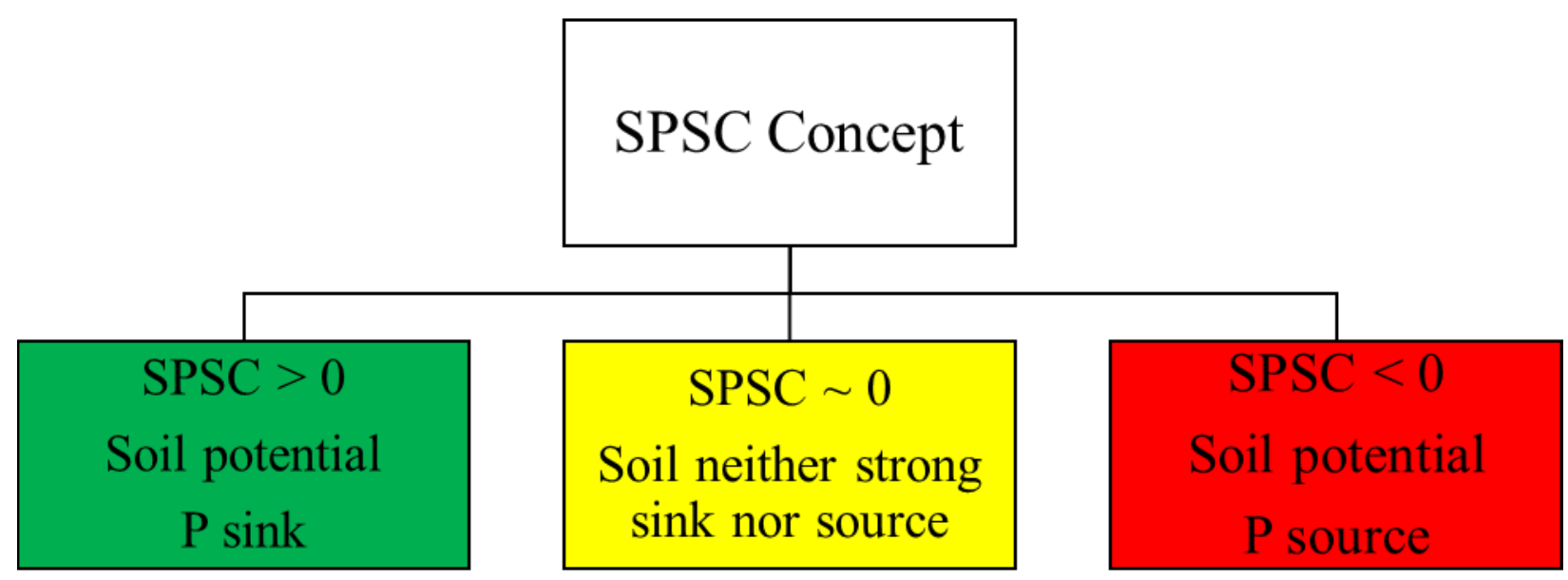

Figure 4. The relationship between SPSC and the remaining capacity for a soil to retain P. The SPSC is related to green, yellow, and red colors to represent potential sink, flow-through, and source $P$ conditions, respectively, relative to the soil storage capacity. Modified from Nair, Clark, and Reddy (2015).

The SPSC concept defines the remaining capacity of the soil to retain additional P. Soils with a positive SPSC have remaining capacity and are potentially good locations for construction of a Poptimal wetland. Soils with near zero or negative SPSC may not be good candidates for a Poptimal wetland or may require further considerations with soil management or amendments. For example, a soil with zero or negative SPSC can either be avoided, removed, or amended. In some cases, a small portion of a potential construction site may be a $\mathrm{P}$ source and may require strategically locating a P-optimal wetland to avoid this area. In other cases, the surface soil may display negative SPSC values, but the subsoil may have a positive SPSC and remaining P storage capacity. In those instances, surface soils removal is recommended to increase P retention.

Finally, use of wetlands for water quality improvements is the result of complex biotic and abiotic factors where transformations, sequestration, and transport pathways interact at the soilwater interface. Soil P retention efficiency depends on $\mathrm{P}$ concentration, water holding time, 
temperature, redox conditions, particulate vs. dissolved $\mathrm{P}$, and other factors. It is therefore important to consider SPSC in the context of complex soil-water interaction and the overall suitability of a potential site for construction of a P-optimal wetland.

ADDITIONAL INFORMATION: Information presented in this technical note was developed under the Great Lakes Restoration Initiative and administered through the Environmental Protection Agency and the USACE Buffalo District. The USACE Program Administrator is Mr. Anthony Friona and the Acting Technical Director is Mr. Warren Lorentz. Technical reviews were provided by Ms. Nia R. Hurst and Mr. Jaybus J. Price (ERDC-EL) and greatly improved the quality of this document.

For additional information contact authors Dr. Christine M. VanZomeren, (Christine.M.VanZomeren@usace.army.mil, 601-634-3702) and Dr. Jacob F. Berkowitz, (Jacob.F.Berkowitz@usace.army.mil, 601-634-5218) or Program Administrator, Dr. Anthony M. Friona (Anthony.M.Friona@usace.army.mil, 716-879-4259).

This technical note should be cited as follows:

VanZomeren, Christine M. and Jacob F. Berkowitz. 2020. Evaluating Soil Phosphorus Storage Capacity in Constructed Wetlands: Sampling and Analysis Protocol for Site Selection. ERDC/EL TN-20-3. Vicksburg, MS: US Army Engineer Research and Development Center.

\section{REFERENCES}

Baker, David B., Laura T. Johnson, Remegio B. Confesor, and John P. Crumrine. 2017. "Vertical Stratification of Soil Phosphorus as a Concern for Dissolved Phosphorus Runoff in the Lake Erie Basin." Journal of Environmental Quality 46, no. 6 (November):1287-1295. doi:10.2134/jeq2016.09.0337.

Berkowitz, Jacob F., Christine M. VanZomeren, Derek Schlea, Tony Friona. 2019. "Phosphorus Fate in Wetlands A Tale of Sources, Sinks, and Soils." International Association of Great Lakes Research Annual Meeting. Brockport, NY.

Currie, Steven J., Christine M. VanZomeren, Jacob F. Berkowitz. 2017. Utilizing Wetlands for Phosphorus Reduction in Great Lakes Watersheds: A Review of Available Literature Examining Soil Properties and Phosphorus Removal Efficiency. ERDC/EL SR-17-4. Vicksburg, MS: US Army Engineer Research and Development Center.

Dari, Biswanath, Vimala D. Nair, Andrew N. Sharpley, Peter Kleinman, Dorcas Franklin, Willie G. Harris. 2018. "Consistency of the Threshold Phosphorus Saturation Ratio across a Wide Geographic Range of Acid Soils." Agrosystems, Geosciences \& Environment 1, no. 1 (September): 1-8. doi:10.2134/age2018.08.0028.

Great Lakes Restoration. 2014. Great Lakes Restoration Initiative Action Plan II.

Mehlich, Adolph. 1984. Mehlich 3 soil test extractant: A modification of Mehlich 2 extractant. Communications Soil Science Plant Analysis. 15:1409-1416. doi:10.1080/00103628409367568.

Merriman, Katherine R. 2015. Development of an Assessment Tool for Agricultural Best Management Practice Implementation in the Great Lakes Restoration Initiative Priority Watersheds-Upper East River, Tributary to Green Bay, Wisconsin (No. 2015-3065). US Geological Survey. https://doi.org/10.3133/fs20153065.

Nair, Vimala D., Willie G. Harris, Debolina Chakraborty, and Myrlène Chrysostome. 2013. Understanding soil phosphorus storage capacity. IFAS Extension, University of Florida, Gainesville, FL: SL336. 
Nair, Vimala D., Kenneth M Portier, Donald A Graetz and M.L. Walker. 2004. "An environmental threshold for degree of phosphorus saturation in sandy soils". Journal of Environmental Quality, 33(1), pp.107-113. doi:10.2134/jeq2004.1070.

Nair, Vimala D., Clark, Mark W. and Reddy, K. Ramesh, 2015. "Evaluation of legacy phosphorus storage and release from wetland soils". Journal of environmental quality, 44(6), pp.1956-1964. https://doi.org/10.1002/clen.201000361

Reddy, K.R., M.W. Clark, R.D. DeLaune, and M. Kongchum. 2013. "Physicochemical characterization of wetland soils." In Methods in biogeochemistry of wetlands. SSSA Book Series No. 10, edited by R.D. DeLaune, K.R. Reddy, C.J. Richardson, and J.P. Megonigal, 41-54. Madison, WI: SSSA. doi:10.2136/sssabookser10.c3.

US Army Corps of Engineers. 2012. "Regional Supplement to the Corps of Engineers Wetland Delineation Manual: North Central and Northeast Region" (Version 2.0), edited by JF Berkowitz, R Lichvar, CV Noble, and JS Wakeley. ERDC/EL TR-12-1.

United States and Canada. 2012. The 2012 Great Lakes Water Quality Agreement: Annex 4. USEPA and Environment Canada. http:// www.epa.gov/glnpo/glwqa/.

VanZomeren, Christine M., Jacob F. Berkowitz, A. Maria Lemke, and Krista G. Kirkham. 2019. "Soil P Storage Capacity in Agricultural Treatment Wetlands: Can a System Designed for N Reduction Also Retain P?." Wetlands (October): 1-12. https://doi.org/10.1007/s13157-019-01205-3.

Vasilas, Lenore M., Jacob F. Berkowitz. 2015. "Identifying Hydric Soils in the Landscape." In Wetland Soils: Genesis, Hydrology, Landscapes, and Classification, edited by Michael J. Vepraskas and Christopher B. Craft. CRC Press.

X-Rite. 2009. Munsell@ Soil Color Charts: Revised edition. Grand Rapids, MI: X-Rite.

NOTE: The contents of this technical note are not to be used for advertising, publication, or promotional purposes. Citation of trade names does not constitute an official endorsement or approval of the use of such products. 


\section{APPENDIX: $\quad$ P-Optimal wetland soil data form}

WETLAND DETERMINATION DATA FORM - Northcentral and Northeast Region

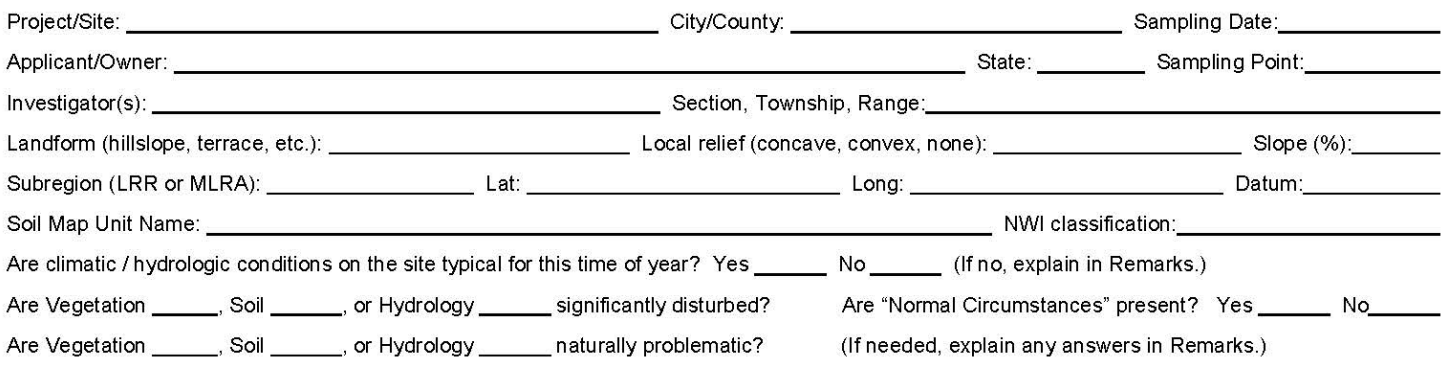

SUMMARY OF FINDINGS - Attach site map showing sampling point locations, transects, important features, etc.

\begin{tabular}{|l|l|l|}
\hline $\begin{array}{l}\text { Hydrophytic Vegetation Present? } \\
\text { Hydric Soil Present? }\end{array}$ & $\begin{array}{l}\text { Yes } \\
\text { No the Sampled Area } \\
\text { Within a Wetland? }\end{array}$ & $\begin{array}{l}\text { No } \\
\text { If yes, optional Wetland Site ID: }\end{array}$ \\
\hline Remarks: (Explain alternative procedures here or in a separate report.) & Yes Nydrology Present?
\end{tabular}

SOIL

Sampling Point:

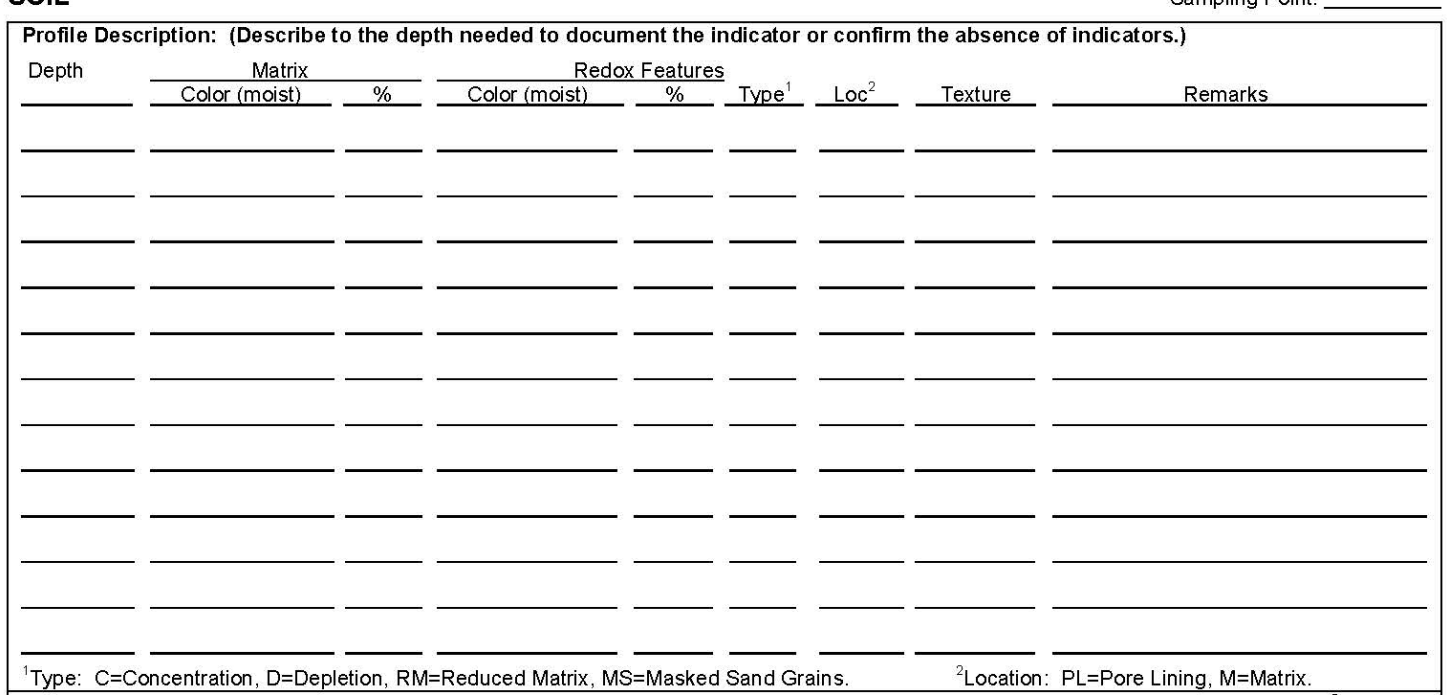

Associated sample bag \#s:

Site photo ID: 